\title{
Research on Public Street Facilities Design in Perspective of City Image
}

\author{
Pingqing Zhang \\ Yantai Nanshan University \\ Yantai, Shandong, China 265713
}

\author{
Yang Wang \\ Yantai Nanshan University \\ Yantai, Shandong, China 265713
}

\begin{abstract}
The design quality of public facilities in urban streets and whether facilities are complete directly embody the quality of space environment in this city and show overall image of the city. At present, the construction of public facilities in urban streets is unsatisfactory in aspects such as decisionmaking, planning and design, development and management. It is extremely urgent to promote construction of facilities in urban streets and shape good city image.
\end{abstract}

Keywords-public facilities in urban streets; regional characteristics; overall environment; city image

\section{INTRODUCTION}

City image is the most valuable intangible assets of a city. Buildings, roads, traffic, tourist attractions and street facilities constantly convey information of many aspects such as nature, history, material and culture. It not only leaves deep impression and feelings on people, but also concerns use and health of citizens, influences the development of politics, economy and culture of a city, even international image of a city, an area and a government and their status on international stage.

\section{CuRrent Situation of DeVelopment of PubliC FACILITIES IN URBAN STREETS OF CHINA AT THE PRESENT STAGE}

The industrialization in our country has a relatively late start, with backward economy and poor urban living environment. Compared with advanced countries such as Europe and America, the development of street facilities is obviously backward. Since the implementation of reform and opening policies, the concept of environmental awareness of people has occurred great changes. People begin to pursue high quality living quality, living environment, free and equal life style more suitable for human nature and maintain living condition, dignity, value, freedom and destiny. But under coexistence of various factors in society and violent impact and influence of modern cultural thoughts, it causes realistic questions of urban landscape environment such as weakening of characteristics of city image, losing of pleasant feelings and deterioration of living environment of human. Construction of public facilities in urban streets is unsatisfactory in many aspects such as decision-making, planning and design, development and management.

\section{A. Form of Facilities Is Single and Unsound}

At present, public facilities in urban streets generally lack excellent design. Most of them have single forms, simple and unpractical. When you go to any city in our country, it is not difficult to find that public facilities in urban streets are more or less unsound on configuration. For example, ancillary facilities in bus shelter are inadequate; or the quantity of information conveyed by information facilities such as indicator and billboard is not enough; or there are few settings. It cannot meet the requirements of different groups of people. Meanwhile, it also directly influences the transmission of overall image in the city.

\section{B. Lack Individualized Design}

The design of existing public facilities in streets lacks consideration for aspects such as geography and culture, nationality and history, tradition and religion, social change and living habits of local residents and the understanding of characteristics of its own. No matter in the south or in the north, in the east or in the west, walking on streets of some cities, we will find public facilities in the street that are similar in color, materials and modeling, which make it difficult to embody the individuality of cities and make these cities lack unique identification.

\section{Lack Humanized Design}

The design of existing public facilities in urban streets pays no attention to survival movement of people outdoors and outdoor living conditions that conform to human nature, lacks pursuit and maintenance of human dignity, freedom and value and consideration for requirements of special users. Harmonious relationships between human and nature, people and people, human and society, human and technology haven't formed. Therefore, public facilities in urban streets cannot be used by people in a convenient, safe, efficient, comfortable and fast way.

\section{The Setting IS Unscientific}

The setting of public facilities in urban streets is established on the basis of close cooperation between city planning management sectors and related government departments. However, for a long time, city construction centers on buildings, pays attention to the design of single building and regards public facilities in streets as accessory of 
buildings. The buildings separate from planning. Some departments simply start from interests, blindly pursue fashion and add randomly, select and settle without analysis. It makes cities and roads crowded and messy; administrators in some departments only pursue achievements in their official career, which directly influence the quality of street facilities.

\section{E. Lack Extension of Historical Context}

Roads, squares, parks, advertisement, street and road names and bill boards of stores in each city convey local cultural information all the time and show "Jing, Qi, Shen" of this city, such as Confucius Temple, Sun Yat-sen Mausoleum, Xinjiekou Business Zone in Nanjing, the Outer Beach, Yellow Crane Tower and Hubu Lane in Wuhan. All of them show cultural connotation of each city and become the epitome of Chinese culture in one region. But the facility design in current urban streets tends to disregard historical context of the city, blindly imitate without analysis, or pursue fashion, or blindly return to the ancients. It makes the overall image of the city do not coordinate and match with street facilities, which destroys the overall image of city environment.

\section{F. Lack Systematic and Innovative Design Concept}

If a city needs to build a bridge, mend a road and construct a row of tall buildings, many people have the enthusiasm. However, not so many people want to participate in building humanized facilities such as public restrooms, greenbelts and barrier-free way, which will not directly bring economic benefits for the city. This is not the problem of money nor ability, but because urban designers and managers lack innovative, sound, developmental and systematic concept.

\section{G. Lack Effective and Unified Management}

There are a wide range of urban street facilities, involving many departments such as industry and commerce, postal service, telecommunications, environmental sanitation, electric power and gardens. So to speak, in any city of China, the situation may be the same. Street lamps and square lamps are governed by urban management departments. Gardening lights and corner lights are governed by botanical garden departments. Public toilets, trash can and setting of rest chair in squares are governed by sanitation departments. Facilities such as booth are governed by commercial departments. Facilities such as telephone booth are governed by information departments. Some public facilities in streets have relationship with many functional departments. The investment and management of different departments lead to disunity of planning and design as well as not high use ratio; different functional departments lack effective communication and collaboration and unified management. Their interest relationships determine incompatibility and diseconomy between different facilities, which make urban residents cannot use in a better, more convenient and comfortable way.

\section{H. The Public Have Weak Environmental Awareness}

The setting of street public facilities shall beautify city. What's more, it should serve the people, make it convenient for people and meet various kinds of requirements of people. But on sidewalk of urban streets, we can see many rest chairs, trash cans, advertising lamp boxes, station boards are destroyed; well lids on both sides of the road disappear; other facilities on the road such as landscape lamps, lawn lamps and fitness equipment on squares are always attacked. Because people have weak environmental awareness, street facilities suffer from different degrees of damage and even are stolen. Meanwhile, it also brings a lot of inconvenience for people's life and communication, damages the image of city and reflects moral quality of residents in this city to some extent.

\section{INFLUENCE OF PUBLIC FACILITIES IN URBAN STREETS ON SHAPING CITY IMAGE}

In order to shape good city image, many cities let people around the world know and understand their city, attract the interest and attention of external publics on the city. They not only have city slogan, city card, landmark of city, city flower, but also make propaganda film to publicize their cities, in order to promote the leading development of industries such as tourism, entertainment, catering and service and drive the comprehensive development of political, economic and cultural undertakings of the city. City image is the embodiment of internal historical connotation and external characteristics of a city. Each element of a city such as buildings, roads, traffic, storefronts and tourist attractions can reflect the look of a city, represent city image and leave deep impression and feelings on people.

If you are invited to talk about the impression that a city leaves on you, what do you remember? How about the environment of this city? Is there anything that leaves a very deep impression on you? How many unique parts did you see? Is the traffic safe, convenient and unblocked? Can you easily identify and find public toilet and bus shelter? Although many cities have a lot of parks, squares, green belts and buildings, the unsatisfactory dustbin, bus shelter, light box of public benefit, telephone booth, public toilet on roadside and bumpy streets still cannot cover up the unnecessary troubles brought by backward street facilities for people. Quite a number of bus stops are only a stark station board without awning, seat and dustbin. Or some awnings don't work. Some citizens open umbrellas to hide away from the sun while waiting the bus. Citizens who don't bring umbrella have to go to shady and cool place nearby, stare at the direction of bus shelter all the time and rush at the bus when the bus arrives at the station. Can this kind of city street facilities leave a good impression on people? If the street facilities designed cannot be used by people in a natural, comfortable, convenient, efficient and safe way and cannot embody regional characteristics of a city, the design will deviate from the right direction.

Cities should make external publics have good psychological feelings through showing charm of their own. When carrying out activities related to this city, people will feel the culture, recreation and high efficiency embodied by humanized and personalized city street facilities, make behavior choice in favor of this city, which boost the competitiveness of this city. So to speak, street facilities in a city are the art of life. It can express comprehensive, different, subjective and identified characteristics with public welfare, highlight unique social and historical cultural environment and unique characteristics of the city and improve popularity of a 
city, provide good external environment for political and economic development. It plays the role of integration internally and propagation externally, manifesting charm of the city.

\section{EXPRESSION FORM OF PUBLIC FACILITY DESIGN IN URBAN STREETS}

With rapid development of cities, the expression forms of street facilities in cities are no longer traditional twodimensional or three-dimensional space forms, but the overall expression forms that integrate time art and spatial art.

\section{A. Meet Deep-seated Spiritual and Cultural Needs of People}

In the past, the design of public facilities in urban streets met the requirements of functions. Now it further rises to spiritual concerns for people. It is the responsibility of designers to emphasize spiritual culture of human in design, endow the design with more meaning and let users understand and feel particularly close through the design with color of metaphor and aesthetic sentiment. When designing, they shall not only pay attention to aesthetic feelings in form and composition, but also analyze and research on social activities and communication behavior of people, make the experience of space conform to functionality of street facilities to meet people's requirements to develop from spiritual and cultural needs to deep-seated and diversified direction, such as the garden-style bus shelter in the ancient city of Suzhou. Its appearance of primitive simplicity and landscape bring out the best in each other, make the construction of urban infrastructure even better, and then make city construction in Suzhou distinctive and contain full-bodied national characteristics.

\section{B. Add Interestingness and Entertainment of Facilities}

A good design shall avoid tedium and have interestingness and key points. The design of street facilities can trigger positive emotional experience and psychological feelings of people and add interestingness and entertainment of facilities through designing changes in shape, color, texture, space, decoration, material and lighting. The nature and characteristics of design should be explicit, specific and materialized through certain modeling. Modeling can increase its expressive force and integrate with colors that have identified, symbolic and decorative functions, make the facilities acquire joyful, agreeable, rich, well-organized and harmonious effects and directly influence emotion and psychology of people.

\section{Pursue Modeling and Dimension Suitable for Body Structure}

In order to make street facilities more individualized and suitable for human body, designers shall emphasize starting from human needs, human emotion and perception as well as interaction between people, make street facilities can have a conversation with people, integrate with users and conform to measure of human and full of the milk of human kindness. Take seats for example. The dimension of ordinary seats is that the height of seat surface is 380 to $400 \mathrm{~mm}$; the width of seat surface is 400 to $450 \mathrm{~mm}$; for the standard length, individual seat is about $600 \mathrm{~mm}$, twin bench-type seat is about $1,200 \mathrm{~mm}$, seat for three people is about $1,800 \mathrm{~mm}$. For back-rest chair, the angle of inclination of backrest is 100 degrees to 110 degrees.

\section{Embody Humanistic Care and Consider Requirements of Disadvantaged Groups}

One of the symbols of modern civilization is to care for disabled persons. Because disabled persons have a variety of inconvenience of the body, they need more help and humanistic care from others. With arrival of aging society in China, at present, facilities for the elders have problems such as uneven distribution and inadequate total quantity. In planning and design, it is necessary to provide barrier free design for disabled persons, perfect the construction of old people's home in central city and improve the level of facilities in surrounding regions of central city. For example, not design steps on the road to improve trafficability of environment; set special smooth ground, road of skid resistance for vulnerable groups and footpath for healthy person; public places should be open to disabled persons and outfit wheelchair; construct special toilets for disabled persons. Perfect their functions and permeate excellent thoughts of human ethics, make users feel warm and sweet, have the sense of warmth and protection and comfortable sensation, create opportunities for them to equally use street facilities, reduce all kinds of sense of grade differential and let them enjoy fairness and social equality. For example, in Japan, public places have convenient facilities and conditions to look after disabled persons. After an electric vehicle used by disabled persons arrives at the station, the bus driver puts down the special-purpose ladder on the bus door and other passengers wait patiently, then the driver push the wheelchair on the bus, help disabled person to settle down and fix the wheelchair; at last, passengers get on the bus in proper order.

\section{E. Humanized and individualized Design Thoughts}

Humanized design is the basis of design of city street facilities. The design cannot rest on the superficial level. Designers shall actively communicate and contact with users and integrate in the life as participant, coordinator, implementer, administrator and experiencer to reflect deepseated and high quality side of humanized design, let the thoughtful, exquisite and humanized design establish harmonious link between human and surrounding environment. Meanwhile, the biggest charm of city image is that it is different from the rest. The national conditions, traditional culture, economic strength and development strategy of each city differ in thousands of ways. These differences embody personalized characteristics of a city. Personalized street facilities distinguish one city from other cities, depict city personality, carry forward urban spirit and spread urban culture.

\section{CONCLUSION}

City image is the public wealth of a city. Public facilities in urban streets shall match and coordinate with this city, show feature of the times, regional characteristics, folk tradition and folk customs of the city, have characteristics suitable for the 
country, nation and region of their own, strengthen emotional connection of people and promote the coordinated, sustainable and healthy development of urban economy, society and culture.

\section{REFERENCES}

[1] Wang Yang, Zhang Pingqing. Discussion on Correlation between Street Facility and City Image [M], Beijing: China Commerce and Trade Press, 2015.

[2] Tang Zhongxi, Xiong Yingjun. Design of Urban Public Environmental Facility [M], Urumqi: Xinjiang Science and Technology Publishing House, 2014.

[3] Written by Simon Bell, translated by Wang Wentong. Visual Design Elements of Landscape [M], Beijing: China Building Industry Press, 2009.

[4] Zhang Dongchu, Pei Xuming. Looking Design of Urban Public Facilities from Industrial Design [J], Urban Problems, 2003(3).

[5] Fu Youlei. Discussion on Influence of Public Facility Design on City Image [J], Art and Design, 2010 (12).

[6] Deng Ding. Discussion on Public Facility Design in City Image Strategy [D], Suzhou: Suzhou University, 2007.

[7] Written by Wang Xiang, Wang Zhu. Design of Urban Environmental Facility Design [M], Shanghai: Shanghai People's Fine Arts Publishing House, 2006.

[8] Kevin Lynch.Reconsidering the image of the city, in City Sense and City Design. Cambridge,Mass:The MIT Press, 1995.

[9] Urban Afairs (ed.), City Branding: Image Building and Building Images. Nai Uitgeversl Publishers, Roterdam, 2002. 